\title{
Producción de Semilla de Papa en Latinoamérica
}

\author{
Fernando N. Ezeta ${ }^{1}$
}

\begin{abstract}
Resumen
Uno de los más importantes avances tecnológicos de la papa en Latinoamérica en las últimas décadas ha sido el desarrollo de métodos para la multiplicación de semilla de papa de alta calidad. En la década de los ochenta el Centro Internacional de la Papa (CIP) generó y difundió intensamente en los sistemas nacionales de investigación agraria (SNIAJ) la tecnología de multiplicación rápida y control de sanidad. Esta tecnología permitió acelerar el proceso de multiplicación de nuevas variedades de papa y la renovación de los núcleos de semilla básica de antiguas variedades a la vez que disminuyó significativamente los costos de producción. En el presente trabajo se analiza el concepto de calidad de semilla y se describe el estado actual de la tecnología, su evolución y adopción en las diversas regiones agroecológicas. Sin embargo, a pesar de los notables logros tecnológicos persisten aun muchas limitaciones para el abastecimiento de semilla de calidad a precios accesibles a la mayoría de los productores. Estas limitaciones son por lo general de orden legal, normativo e institucional aunque persisten algunas ineficiencias productivas que podrían ser superadas mediante intervenciones tecnológicas. Se ofrecen algunas recomendaciones para el desarrollo de la producción de semilla en la región.
\end{abstract}

Palabras claves adicionales: Semilla de papa, multiplicación, Producción.

\section{Potato Seed Production in Latin America}

\section{Summary}

One of the most important technological advances of potato in Latin America in the last decades has been the development of methods for

\footnotetext{
${ }^{1}$ Representante Regional para Latinoamérica y el Caribe. Centro Internacional de la Papa (CIP), Apartado 1558, Lima 12, Perú.
} 
multiplication of high quality potato seed. During the eighties the International Potato Center (CIP) generated and intensively diffused among the national agricultural research systems (NARS) the techniques for rapid multiplication and pathogen testing of clonal seed. These technologies accelerated the multiplication of new potato varieties and the renewal of basic seed stocks of old varieties and significantly reduced production costs. This paper analyses the concept of seed quality and the state of the art of seed production technology in Latin America and its evolution and adoption in the diverse agroecologies of the region. Nevertheless, in spite of this remarkable technological advance there are still many limitations to a stable supply of quality potato seed to most potato growers. These limitations are mostly of legal, normative and institutional orders although some inefficiencies in the production process still persist that could be overcome by means of technological interventions. Some recommendations for the development of the seed production industry in the region are provided.

Additional Index words:

Potato seed, multiplication, production.

\section{Introducción}

En las últimas décadas la producción de semilla de papa en Latinoamérica ha experimentado extraordinarios avances gracias al desarrollo de los métodos de multiplicación rápida, utilizando secciones de tallo enraizadas o plántulas in vitro multiplicadas masivamente, y a las técnicas de eliminación de patógenos, por medio del cultivo de meristemas y termoterapia (Bryan J. et al, 1983). Paralelamente se desarrollaron métodos serológicos y de hibridación de ácidos nucleicos para la detección de patógenos, especialmente de los virus y viroides que, por su presencia sistémica en la planta, se difunden fácilmente por medio de la multiplicación vegetativa. Esta tecnología generada y difundida por el Centro Internacional de la Papa (CIP) desplazó rápidamente los métodos tradicionales de multiplicación clonal disminuyendo tiempo y costos para la obtención del material básico, élite, inicial o fundamental como se denomina a los tubérculos-semillas que los centros o estaciones experimentales entregan a los multiplicadores de semilla. 
Durante la década de los ochenta, los métodos de multiplicación rápida y de detección de patógenos por serología se difundieron ampliamente en Latinoamérica mediante un intensivo programa de capacitación auspiciado por el CIP. Se estima que desde 1972 hasta 1992 aproximadamente 2,000 profesionales latinoamericanos recibieron capacitación general o especializada en producción de semilla y disciplinas relacionadas a la multiplicación y la sanidad. En este mismo período varios países tomaron la decisión de reducir sus importaciones de semilla con la finalidad de ahorrar divisas y otros no importadores decidieron mejorar la calidad de su semilla. Ambas situaciones condicionaron la introducción y difusión agresiva de estas tecnologías por los programas nacionales de papa de las instituciones públicas y en muchos casos por el sector privado.

La gran diversidad de situaciones agroclimáticas y tecnológicas en las cuales se han introducido los métodos de multiplicación rápida en América Latina ha resultado en un gran número de valiosas experiencias que han contribuido a mejorar y adaptar los nuevos métodos a las situaciones particulares de cada país o región productora. Sin embargo, en algunos casos persisten aún factores que limitan el uso extensivo de estas tecnologías y en otros se han sobredimensionado los programas de semilla de tal manera que no guardan relación con la demanda y las necesidades reales del país.

Este documento analiza en forma genérica las experiencias en producción de semilla en América Latina y las limitaciones para la mayor difusión de las tecnologías modernas de multiplicación rápida y control de la sanidad. También se presentan recomendaciones para mejorar los sistemas de producción de semilla.

\section{El concepto de calidad de semilla}

Para iniciar una discusión sobre el tema de semilla de papa se hace indispensable definir previamente el concepto de calidad de semilla. Los productores califican la calidad de semilla de mala o buena según un conjunto de criterios a los cuales atribuyen diversos grados de importancia según experiencias y necesidades particulares. Para muchos agricultores el tamaño de la semilla es un criterio muy importante por su relación con el costo unitario o por la exigencia de la siembra mecánica. Otros dan mucho valor a la procedencia de la semilla identificando la calidad con la localidad de producción. En algunos casos se considera la apariencia externa del tubérculo, estado de conservación, brotamiento y presencia de síntomas visuales de plagas y enfermedades. Ocasionalmente se recurre 
al análisis de enfermedades viróticas por métodos serológicos. En realidad todas estas observaciones son apreciaciones parciales de un concepto integral de calidad que incluye dos grandes grupos de factores relacionados a la fisiología y a la sanidad. Estos factores tienen íntima relación con las condiciones climáticas del lugar de producción, con el proceso productivo mismo y con el manejo poscosecha de la semilla.

La relación entre el estado fisiológico y el potencial productivo es bien conocida (Beukema H.P. y Van der Zaag D.E., 1979) La semilla producida en climas fríos exhibe una curva de crecimiento más amplia y un mayor potencial productivo que la semilla producida en climas cálidos. El concepto de edad fisiológica fue introducido para explicar este comportamiento diferencial de la semilla por su grado de envejecimiento fisiológico. Algunos otros factores ambientales y de manejo de la producción y la poscosecha influyen sobre la edad fisiológica de la semilla y consecuentemente sobre su precocidad y productividad. Entre los factores que inducen al envejecimiento fisiológico en la fase de producción están el foto período de días cortos y la alta temperatura, el déficit hídrico y la baja fertilización nitrogenada de las plantas madre y durante la fase de almacenamiento, principalmente la alta temperatura. Los tratamientos con hormonas y reguladores de crecimiento también influyen sobre la edad fisiológica de la siguiente generación.

La sanidad también guarda estrecha relación con los factores climáticos y ambientales de los centros de producción. Los mejores lugares para la multiplicación son aquellos que por sus condiciones climáticas y por su aislamiento de otros cultivos permiten producir semilla bajo la mínima presión de infección de enfermedades transmitidas por diversos vectores, de los cuales los más conocidos son los áfidos. Estas condiciones se consiguen en regiones de mayor latitud tanto en el hemisferio norte como en el sur o por medio de la altura en los países situados en los trópicos y subtrópicos. En América Latina se presentan ambas situaciones. Argentina y principalmente Chile presentan condiciones excepcionales para la multiplicación de semilla en sus regiones australes. Los países andinos recurren a las zonas altas para producir sus semillas e igualmente ocurre en varios países centroamericanos. En México así como en Argentina se utilizan ambos recursos, es decir la altura y la latitud o una combinación de ambos factores.

Las óptimas condiciones climáticas deben ser complementadas con adecuadas prácticas productivas y conveniente manejo poscosecha. 
La sanidad depende también de las prácticas agronómicas, desde la selección del campo y de la semilla, el descarte de plantas atípicas o con síntomas de enfermedades, el control de plagas y enfermedades, durante el crecimiento; y la cosecha oportuna y selección antes del almacenamiento en condiciones adecuadas.

\section{La tasa de multiplicación}

Uno de los factores limitantes para la difusión de nuevas variedades así como para la renovación de semilla de las variedades comerciales es la baja tasa de multiplicación vegetativa de la papa. En América Latina la tasa promedio de multiplicación a campo es de 1:5 fluctuando entre extremos de 1:3 hasta 1:10 en las mejores condiciones. Sin embargo, en algunos países especializados en producción de semilla en Europa y Norteamérica esta tasa se aproxima a 1:20 gracias a prácticas agronómicas y manejo poscosecha de los tubérculos madre que permiten aumentar el número de tubérculos de tamaño semilla $(60-80 \mathrm{~g})$ por unidad de área. En vista de que existe una relación directa entre el número de tallos por unidad de área y el número de tubérculos producidos, los productores de semilla pueden ajustar la densidad de siembra a fin de obtener un mayor número de tubérculos para semilla. Otra posibilidad de mejorar la eficiencia en la multiplicación es el uso de semilla fisiológicamente envejecida que permite acelerar el ciclo vegetativo, reducir la dominancia apical y favorecer la producción de tallos con lo que se consigue una mayor proporción de tubérculos de tamaño apto para semilla (Beukema, H.P y Van der Zaag, D.E. 1990). No obstante estas consideraciones, el número de tubérculos producidos por tallo o por tubérculo madre es un factor genético que no es siempre tomado en cuenta por los mejoradores de papa. En el afán de conseguir tubérculos grandes y alargados para la industria de la papa frita, algunas de las variedades han sido seleccionadas para producir pocos tubérculos lo que resulta en bajas tasas de multiplicación difícilmente superables mediante prácticas agronómicas.

En los países andinos una práctica muy frecuente es la selección de los tubérculos grandes para el mercado de consumo mientras que los tubérculos medianos o pequeños se destinan a semilla. Esta práctica es muy difundida aún entre los semilleristas especializados en las primeras multiplicaciones de la semilla básica. De esta manera aproximadamente el $50 \%$ de la multiplicación de semilla de alta calidad se deriva al mercado de consumo y sólo $50 \%$ continua el proceso de multiplicación. Lamentablemente esta práctica permite que se pierda valioso material contribuyendo a reducir drásticamente la tasa de multiplicación y a elevar los costos de los programas de semilla. 


\section{La tasa de renovación de semilla}

En condiciones climáticas favorables y bajo buen manejo agronómico es posible mantener la semilla en buenas condiciones fisiológicas y sanitarias por una o más generaciones antes de recurrir a la compra de nueva semilla. Existen pocos casos en Latinoamérica en que los productores necesiten renovar su semilla anualmente debido a condiciones climáticas desfavorables o a dificultades para almacenarla hasta la próxima siembra. Los productores de los Andes, gracias a la altura, y los de las regiones australes gracias a la latitud, gozan de condiciones ambientales adecuadas para la multiplicación y el almacenamiento de semilla. En tales condiciones la renovación de semilla se hace después de varias siembras o cuando la pérdida en productividad es importante en términos económicos. En las zonas subtropicales y en las laderas bajas de los Andes y Centro América la tasa de renovación es más frecuente debido a las condiciones climáticas favorables a la diseminación de plagas y enfermedades y a la degeneración fisiológica. En los países que importan semilla desde Europa y Norteamérica, se suele multiplicar esta semilla dos o tres veces antes de recurrir a nuevas importaciones.

\section{El modelo básico de multiplicación rápida y sus innovaciones}

El modelo básico de multiplicación rápida consiste en la producción de minitubérculos a partir de esquejes enraizados y trasplantados a macetas o almácigos con sustrato esterilizado. Los esquejes generalmente son tomados de plantas-madre libres de patógenos obtenidas por vía del cultivo de meristemas previo tratamiento de termoterapia. La producción de minitubérculos se hace en ambientes protegidos por malla antiáfidos y el producto recibe la denominación de semilla prebásica que, al ser multiplicada en el campo, da origen a la primera generación de semilla básica. Este modelo ha sufrido diversas modificaciones resultantes de desarrollos tecnológicos o de la necesidad de ajustarlo a situaciones particulares a cada centro de producción. Algunas de estas modificaciones han contribuido a mejorar la calidad y eficiencia del modelo. Otras, sin embargo, han aumentado el riesgo de contaminación o disminuido la eficiencia productiva. La primera variación fue la utilización de plántulas in vitro en vez de esquejes enraizados para la producción de minitubérculos. 
Esta innovación fue posible gracias al desarrollo de métodos de laboratorio que facilitaron la producción masiva de plántulas a partir de secciones de tallo en medio de cultivo. La condición juvenil del material in vitro generalmente resulta en una alta capacidad productiva de minitubérculos por unidad de superficie. Los rendimientos se sitúan entre 300 y 800 tuberculillos por $\mathrm{m}^{2}$ pudiéndose obtener hasta tres cosechas por año. Sin embargo, algunas variedades son de baja productividad en condiciones de invernadero.

La eficiencia productiva en los invernaderos ha mejorado substancialmente con el uso de equipos presurizados de riego, el control de temperaturas medias, máximas y mínimas, foto período, luminosidad, fertilización y sustratos adecuados. Se conocen algunos casos en que se han instalado sistemas de alta precisión para el control de los factores ambientales de mayor incidencia en la producción incluyendo el enriquecimiento del aire con $\mathrm{CO}_{2}$. En estas instalaciones es posible realizar cosechas progresivas de los tuberculillos una vez que alcanzan un tamaño mínimo deseado.

La ganancia en eficiencia se ha traducido en significativa reducción de costos unitarios. Actualmente algunos centros de producción reportan costos inferiores a US\$0.20 por unidad. En Latinoamérica el precio fluctúa entre US\$0.20 y 0.60 por unidad de tuberculillo mayor de 5 gramos. Un reciente trabajo de investigación en Cajamarca-Perú ha encontrado un costo promedio de US\$0.041 por unidad de tubérculo de semilla pre-básica en los centros de investigación y producción de semilla del ámbito en estudio en la sierra norte del Perú. Sin embargo, estos costos extremadamente bajos pueden estar subestimando el componente de control de calidad y los costos fijos iniciales fuertemente subsidiados por el sector público. La producción masiva de plántulas in vitro requiere de instalaciones apropiadas y de personal calificado, costos que por lo general no son adecuadamente cuantificados en el análisis económico en las instituciones públicas.

Otra modificación substancial al modelo ha sido el trasplante directo al campo de plántulas in vitro. En este caso las plantas pasan por un período de adaptación en ambientes protegidos de la radiación solar directa donde son trasplantadas en algún sustrato que permite el desarrollo radicular y la aclimatación de la plántula antes del trasplante definitivo al campo. Este método ha sido probado en varios países, pero la mayoría de ellos lo han abandonado por las dificultades en el manejo de las plántulas, baja tasa de sobrevivencia y alto costo entre otros. 


\section{Otros métodos de multiplicación rápida}

La producción de microtubérculos in vitro surgió como una alternativa a los minitubérculos. La tuberización in vitro ha sido ampliamente estudiada siendo posible la producción de grandes cantidades en pequeños ambientes. Sin embargo, las dificultades en el manejo, almacenamiento y brotamiento han sido limitantes para el uso práctico de esta metodología. Los microtubérculos son muy susceptibles a la deshidratación durante el almacenamiento y son además difíciles de brotar aún utilizando substancias químicas estimulantes.

En los últimos años se ha difundido en Perú, Ecuador y Bolivia la metodología de enraizamiento de brotes o retoños. Este método consiste en tomar brotes vigorosos de los tubérculos expuestos a luz difusa y enraizarlos en algún sustrato adecuado. Una vez enraizado, este material es llevado directamente al campo donde su sobrevivencia es muy alta gracias al vigor del material. Este método aumenta significativamente las tasas de multiplicación de la categoría básica.

\section{Los sistemas artesanales}

Tanto en los países andinos como en los no-andinos existen sistemas artesanales de producción de semilla que abastecen gran parte de la demanda. En los países andinos los sistemas artesanales abastecen más del $95 \%$ de las necesidades de semilla mientras que en los países noandinos donde la papa no es el cultivo tradicional los sistemas tecnificados tienen mayor participación en el mercado de semillas.

La producción artesanal de semilla se fundamenta en el conocimiento tradicional que la calidad esta dada por las condiciones ambientales adecuadas para la multiplicación de semilla. En algunos casos los productores adicionalmente aplican selección positiva y descarte de las plantas con síntomas de enfermedades de sus campos de producción. En este sistema también se utiliza el descanso de terrenos y la rotación de cultivos para recuperar la fertilidad de los suelos y disminuir la incidencia de plagas. La calidad de semilla producida en el sistema artesanal puede ser muy buena como lo demuestran muchos ensayos comparativos con la semilla tecnificada (Monares, A., 1979; Monares, A., 1981). Muchos programas de semilla en América Latina han adoptado el sistema tecnificado sin estudios previos de factibilidad económica y desestimando 
la competitividad de los sistemas artesanales. En la región andina es frecuente encontrar que los altos costos del sistema tecnificado no pueden ser justificados por aumentos en la productividad motivando el desinterés de los productores por esta semilla y su retorno al sistema artesanal.

\section{Desarrollo sub-regional de la producción de semilla}

La tecnología de multiplicación rápida para la producción de semilla prebásica fue introducida y difundida inicialmente en el Perú, en 1983, por medio de un proyecto especial financiado por la Cooperación Técnica Suiza, COTESU, con el apoyo técnico del CIP. Luego surgieron otros proyectos similares en Bolivia y Ecuador que tenían entre sus objetivos principales el mejoramiento de la calidad de la semilla. Mediante estos proyectos se consiguió dotar a los programas nacionales de papa con la infraestructura básica para el cultivo de tejidos, la multiplicación rápida en casas de vegetación y el control de calidad fitosanitaria. Paralelamente se capacitó a muchos profesionales en las técnicas de cultivo de tejidos, virología y manejo de invernaderos. En etapas posteriores se estudiaron los sistemas de producción andinos para entender los mecanismos de abastecimiento de semilla de los diversos tipos de productores, la tasa de renovación y los flujos de semilla en los sistemas artesanales. Las experiencias de estos proyectos fueron transferidas horizontalmente entre los países andinos por medio de la red PRACIPA, Programa Cooperativo de Investigación en Papa, financiada en sus primeras etapas por la cooperación canadiense (IDRC) y posteriormente integrada al PROCIANDINO. En Venezuela se desarrolló un proyecto especial a través de la Junta del Acuerdo de Cartagena para generar variedades y multiplicar semilla. Estas experiencias de la sub-región andina permitieron extraer algunas conclusiones importantes. En primer lugar se determinó que la semilla producida por métodos artesanales podía ser de muy buena calidad y competir en productividad con la semilla proveniente de los programas tecnificados. Adicionalmente se determinó que las enfermedades viróticas no eran la única ni la más importante causa de la pérdida de vigor y productividad de la semilla en los Andes (Fankhauser, C., 2000). Otros factores patológicos y fisiológicos agregados debían ser tomados en cuenta por su importancia relativa en la degeneración de la semilla en función de la variedad, del lugar de producción y del manejo poscosecha. Sin embargo, no cabe duda que la resistencia genética a virus es un factor determinante de la estabilidad productiva de algunas variedades nativas y mejoradas. 
En resumen, la tecnología de producción de semilla está ampliamente difundida en los países andinos tanto en el sector público como en el sector privado. En los primeros años fue el sector público que incorporó la tecnología en los centros experimentales pero progresivamente se ha difundido al sector privado con gran eficiencia y sostenibilidad. Si bien el área cubierta con semilla certificada procedente de sistemas supervisados por los entes oficiales es pequeña, la tecnología de multiplicación rápida ha permitido difundir eficientemente nuevas variedades y reintroducir antiguas variedades a los sistemas de producción. La interacción de los sistemas tecnificados y artesanales permite suponer que la influencia de un programa tecnificado sobrepasa los valores de cobertura estimados por las estadísticas oficiales de producción.

En el Cono Sur la tecnología de multiplicación rápida se adoptó algunos años después que en los países andinos. Chile, Argentina, Uruguay y Brasil iniciaron casi paralelamente sus programas de desarrollo de infraestructura y de capacitación de personal. En esta sub-región el sector privado tuvo destacada participación desde el inicio aunque también fue importante el aporte del sector público. En la actualidad las unidades de producción de semilla prebásica pueden estar integradas al sistema de producción de una empresa productora de semilla o pueden ser unidades especializadas en producción de plántulas in vitro 0 tuberculillos prebásicos y en servicios conexos a la producción de semilla certificada. El conjunto de técnicas de multiplicación y control de calidad adoptadas por estos países les permitió modernizar sus sistemas de producción de papa con consecuentes mejoras en la productividad. Los países importadores de semilla consiguieron reducir sus importaciones y los programas de mejoramiento consiguieron difundir algunas variedades generadas localmente.

En México, Centro América y el Caribe que es el área de operaciones del Programa Cooperativo para el Desarrollo de la Papa (PRECODEPA) se han alcanzado notables avances en la producción de semilla gracias a la tecnología. La difusión regional de variedades generadas 0 seleccionadas localmente como Atzimba en México y Floresta en Costa Rica no hubiera sido posible sin la capacidad regional para mantener y multiplicar semilla de calidad. En México y Costa Rica el sector privado se ha destacado por la fuerte participación en la producción de semilla prebásica integrada a la producción de semilla de alta calidad. En Cuba se desarrolló intensamente la tecnología para la multiplicación masiva in vitro por lo que este país ha ejercido el liderazgo en el ámbito de PRECODEPA en lo referente a la producción de semilla. 


\section{Debilidades en los sistemas de producción de semilla en América Latina}

Aunque existen grandes diferencias entre los países latinoamericanos hay un número de factores que limitan el desarrollo de la industria de semilla. A continuación se presenta una lista de las más frecuentes.

- Incumplimiento de leyes y reglamentos de semilla.

- Obsolescencia o inaplicabilidad de las normas legales.

- Indefinición de responsabilidades institucionales para la supervisión y el control de calidad.

- Inestabilidad del personal capacitado para producción de semilla prebásica en las instituciones públicas.

- Debilidad de las asociaciones de productores.

- Poca coordinación entre oferta y demanda para definir qué se multiplica, dónde y cuánta semilla pre-básica o básica se necesita.

- Competencia entre el sector público y el sector privado en la producción de semilla.

- Sobredimensionamiento de la infraestructura para producción de semilla prebásica.

- Baja eficiencia productiva en laboratorios, invernaderos y campo.

- Elevado costo de producción.

- Inestabilidad de precios.

- Fuga de semilla del sistema formal hacia el mercado de consumo.

- Deshonestidad de intermediarios en el mercado de semilla.

\section{Riesgos derivados de la falta de buenos sistemas de semilla}

El riesgo más evidente e inmediato consiste en la diseminación de enfermedades, principalmente aquellas sistémicas causadas por virus, viroides, fitoplasmas y bacterias, por medio del movimiento descontrolado de semillas dentro de un país. Este riesgo se extiende también a la introducción de plagas y enfermedades exóticas desde países vecinos o aún desde otro continente. 
El lamentable caso de la polilla (Tecia solanivora) que se está extendiendo en el continente es un dramático ejemplo del riesgo que implica el movimiento de semilla sin las debidas precauciones y controles fitosanitarios. Otro riesgo es la incapacidad de reaccionar con rapidez y eficiencia a los cambios en la demanda inducidas por las oportunidades en la industria y la exportación o nuevas condiciones climáticas que requieren la difusión de variedades mejor adaptadas y productivas, de mejor calidad y más resistentes a plagas y enfermedades. Por último está el riesgo de perder competitividad sea por la caída en la productividad o por el aumento de los costos unitarios de producción.

\section{Recomendaciones}

La primera recomendación consiste en reconocer que los sistemas tecnificado y artesanal no son mutuamente exclusivos y que deben coexistir en armonía beneficiándose mutuamente (Thiele G.,1997). El sistema artesanal en la subregión andina está basado en el conocimiento ancestral sobre la interacción de las condiciones ambientales con la sanidad y el estado fisiológico de los tubérculos semilla. Por otro lado, la tecnología moderna puede añadir valiosos componentes al proceso productivo para garantizar la calidad y disminuir los costos (Prain, G. and Scheidegger, U., 1987 ; Scheidegger et al, 1989).

El rol del Estado debe ser definido como normativo, orientador, promotor y supervisor evitando competir con el sector privado en la producción. Sólo se justificaría la intervención estatal en caso de que el sector privado no muestre interés en la multiplicación de algunas variedades de poco valor comercial, pero con importancia estratégica social o económica en el ámbito nacional o regional.

La certificación de semilla no debe ser compulsoria sino más bien un mecanismo de control externo de calidad al cual acceden los productores voluntariamente. El Estado debe fomentar la creación de empresas de servicios que brinden asistencia técnica en producción de semilla y certificación de calidad. Esto de ninguna manera debe limitar su capacidad de normar y ordenar el sistema en salvaguarda de los intereses nacionales (Garay et al, sin fecha).

Debe promoverse la negociación directa entre los productores y los consumidores de semilla. De esta manera disminuiría la excesiva participación de intermediarios en la comercialización quienes, por ser ajenos al proceso productivo, generalmente no se responsabilizan por la calidad del producto. Las asociaciones de productores pueden jugar un rol importante en estas transacciones. 
Otra medida que permite una comunicación más fluida entre la oferta y demanda y perfecciona el mercado son los sistemas de información confiables y fácilmente accesibles a productores y consumidores.

Se recomienda aumentar la eficiencia en todas las fases de la producción de semilla con la finalidad de reducir el costo unitario. Esto puede requerir más que el aumento en la productividad, por ejemplo también es posible corregir ineficiencias en la planificación, almacenamiento y comercialización.

El valor de un sistema bien organizado de semilla no debe medirse únicamente por las ganancias en producción, también hay que considerar otros aspectos como la estabilidad de la producción, la disminución de riesgos de diseminación de plagas y enfermedades y la capacidad de un país para responder, por medio del mejoramiento genético y la biotecnología, a las exigencias de mercados globalizados, cambios climáticos inducidos e intensificación de la agricultura.

\section{Referencias Bibliográficas}

1. Beukema H.P.; Van der Zaag, D.E. 1990. Introduction to Potato Production, Pudoc Wageningen, The Netherlands.

2. Beukema H.P.; Vander Zaag, D.E. 1979. Potato Improvement, some factors and facts, International Agricultural Center. I.A.C. Wageningen, The Netherlands.

3. Bryan, J.E.; Jackson, M.T.; Meléndez, N. 1983. Rapid Multiplication Techniques for Potatoes. CIP, Lima, Perú.

4. Fankhauser, C. 2000. Baja incidencia de los virus en Ecuador: Nuevas perspectivas para la producción de semilla de papa en las zonas altas del trópico. Resúmenes del XIX Congreso de la Asociación Latinoamericana de la Papa, Habana, Cuba.

5. Garay, A.; Pattie, P.; Landivar, J.; Rosales, J. (sin fecha). Setting a Seed Industry in Motion: A nonconventional, successful approach in a developing country. Working Document No. 57, CIAT, Cali, Colombia.

6. Monares, A. 1979. Agroeconomic evaluation of highland seed in the Canete Valley, Perú. Social Science Unit, Working Paper Series, CIP, No. $1979-3$ 
7. Monares, A. 1981. The Potato Seed System in the Andean Región: The Case of Perú. Ph.D Thesis. Cornell University. Ithaca, New York. USA.

8. Prain, G.; Scheidegger, U. 1987. User -friendly seed programs. Report of the Third Social Science Planning Conference, September 7-10. CIP,Lima, Perú.

9. Scheidegger, U.; Prain, G.; Ezeta, F.; Vittorelli, C. 1989. Linking formal R\&D to indigenous systems: a user oriented seed program for Perú. Network Paper 10, ODI, London.

10. Thiele, G. 1997. Sistemas Informales de Semilla de Papa en los Andes: ¿Por qué son importantes y qué hacer con ellos?. Documento de Trabajo 1997-1, Departamento de Ciencias Sociales, Centro Internacional de la Papa, Lima, Perú. 